\title{
Appraisal of the Treponema pallidum haemagglutination test
}

\author{
A. LUGER AND I. SPENDLINGWIMMER \\ Department of Dermatology, Vienna City-Lainz Hospital
}

Several attempts have been made to use haemagglutination reactions for the diagnosis of syphilis between 1932 and 1958. The first reliable method was developed by Rathlev (1965). Further results of investigations with this method have been reported by authors from Japan and from the Venereal Disease Research Laboratory in Atlanta, U.S.A. Rathlev prepared the reagents for the test in the Statens Seruminstitut, Copenhagen, Denmark, but the other investigators used reagents obtained from Fujizoki, Tokyo, Japan. This paper presents the first results of the TPHA test obtained in the Serodiagnosis Laboratory at the Department of Dermatology in the Vienna City-Lainz Hospital.

\section{Material and methods}

500 sera were evaluated in the FTA-ABS, in the VDRL, and in the TPHA test. Complement-fixation, Kahn, and MKR III tests were performed on all samples, but the results of these tests have not been included in this report.

The TPHA test was carried out with inactivated sera. Otherwise the method was that of Tomizawa and Kasamatsu (1966) and Tomizawa (1968) and included controls with non-sensitized sheep-erythrocytes. Quantitative tests were performed on all sera reactive in the VDRL and in the TPHA test. The dilutions were $1: 1,1: 2,1: 4,1: 8$, etc., in the VDRL test and $1: 80,1: 320,1: 1,280,1: 5,120$, etc., in the TPHA test.

\section{Results and discussion}

The TPHA test was reactive in 318 (63.6 per cent.) of the 500 sera. Reactivity in the FTA-ABS test was found in 279 ( 55.8 per cent.). The general agreement rate was therefore $87 \cdot 7$ per cent. However, 44 (19.9 per cent.) of the 221 samples which were nonreactive in the FTA-ABS test were reactive in the TPHA test whereas only five ( 1.8 per cent.) of the 279 sera which were reactive in the FTA-ABS test were nonreactive in the TPHA test, indicating that the TPHA test is much more sensitive.
A cross-evaluation of the TPHA and the VDRL tests revealed, as expected, a much greater divergence. Reactivity in the VDRL test was found in 221 (44.2 per cent.) of the 500 sera. The general agreement rate was 69.4 per cent., but 125 ( 44.8 per cent.) of the 279 samples which were nonreactive in the VDRL test were reactive in the TPHA test, whereas only $28(12 \cdot 7$ per cent.) of the 221 sera which were reactive in the VDRL test did not react in the TPHA test.

Agreement with the TPHA test was greatest in the group of sera which were reactive in the VDRL and FTA-ABS tests.

Discrepancies were found mainly in sera which were nonreactive in the VDRL or FTA-ABS tests, but reactive in the TPHA test.

The quantitative evaluation showed titres ranging between dilutions of 1 and 128 in the VDRL test and between dilutions of 80 and 327, 680 in the TPHA test. There was a reasonably good correlation at all dilutions. This differs somewhat from the findings of Uete, Fukazawa, Ogi, and Takeuchi (1971), who observed a good correlation at high titres only.

The test results of 102 syphilitic patients could be compared with the clinical stages of the disease. The diagnosis was confirmed by darkfield examination in all the 21 cases of primary and five cases of secondary syphilis. The group with latent syphilis comprised 68 patients who had already been adequately treated for early or latent syphilis. One suffered from neurosyphilis and the seven congenital syphilitics were mainly late cases.

The Table provides information on the reactivity in the different tests at the various stages of the disease. Of the 102 sera, 101 (99 per cent.) were reactive in the TPHA test. The reactivity rate was 86.2 per cent. in the FTA-ABS test and $59 \cdot 8$ per cent. in the VDRL test.

Reactivity after infection began sooner in the TPHA test than in the FTA-ABS and VDRL tests, the reactors numbering twenty, sixteen, and ten respectively in the group with primary syphilis. 
TABLE Reactivity at different stages of syphilis

\begin{tabular}{|c|c|c|c|c|}
\hline \multirow[b]{2}{*}{ Diagnosis } & \multirow{2}{*}{$\begin{array}{l}\text { No. of } \\
\text { patients }\end{array}$} & \multicolumn{3}{|c|}{ No. of patients reactive in the } \\
\hline & & TPHA & $F T A-A B S$ & $V D R L$ \\
\hline $\begin{array}{l}\text { Primary } \\
\text { syphilis } \\
\text { Secondary }\end{array}$ & 21 & 20 & 16 & 10 \\
\hline $\begin{array}{l}\text { syphilis } \\
\text { Latent }\end{array}$ & 5 & 5 & 5 & 5 \\
\hline syphilis & 68 & 68 & 59 & 40 \\
\hline $\begin{array}{l}\text { Neurosyphilis } \\
\text { Congenital }\end{array}$ & 1 & 1 & 1 & - \\
\hline syphilis & 7 & 7 & 7 & 6 \\
\hline Total No. & 102 & 101 & 88 & 61 \\
\hline Per cent. & 100 & 99 & $86 \cdot 2$ & $59 \cdot 8$ \\
\hline
\end{tabular}

On the other hand, reactivity after successful treatment of early syphilis persisted much longer in the TPHA test than in the others. This is reflected in the results in the group with latent syphilis; all 68 sera in this group were reactive in the TPHA test, compared with 59 in the FTA-ABS test and only forty in the VDRL test.

\section{Summary and conclusions}

Five hundred sera were evaluated in the FTA-ABS, VDRL, and TPHA tests, and the results of the tests were correlated with the stage of disease in 102 patients with syphilis. The findings permit the conclusion that the TPHA test is more sensitive than the FTA-ABS test. Further studies will be necessary to determine how far this comparatively simple test can be used to replace the difficult and expensive TPI test.

The TPHA test is very useful in the detection of latent syphilis and the diagnosis of biological false positive reactions in tests employing lipoidal antigens. The rise and fall of the TPHA titres are of only limited value with regard to conclusions on the activity of the disease or on the influence of treatment on antigen production. It will therefore still be necessary to use the quantitative VDRL test for the assessment of the efficacy of antisyphilitic therapy.

\section{References}

RATHLEV, T. (1965) WHO VDT/RES/77.65

Tomizawa, T. (1968) fap. clin. Med., 26, 304

- and Kasamatsu, S. (1966) fap. F. med. Sci. Biol., 19, 305

Uete, T., Fukazawa, S., Ogi, K., and Takeuchi, Y. (1971) Brit. f. vener. Dis. 47, 73

\section{Une appréciation du test d'hémagglutination du} Treponema pallidum (TPHA)

SOMMAIRE ET CONCLUSIONS

Cinq cents sérums furent évalués vis-à-vis des tests FTA-ABS, VDRL, TPHA, et les résultats de ces tests furent classés selon le stade de la maladie chez 102 syphilitiques. On conclut des résultats que l'épreuve TPHA est plus sensible que le FTA-ABS. Des études supplémentaires seront nécessaires pour établir jusqu'à quel point ce test relativement simple peut remplacer le difficile et côuteux TPI.

Le test TPHA est très utile pour la détection de la syphilis latente et pour le diagnostic des réactions biologiques faussement positives observées avec les épreuves utilisant les antigènes lipidiques. La montée et la baisse des titres TPHA m'ont qu'une valeur limitée pour déterminer l'activité de la maladie ou l'influence du traitement sur la production antigénique. Il est donc toujours nécessaire de recourir au test VDRL quantitatifpour évaluer l'efficacité d'un traitement antisyphilitique. 